\title{
Biology, Life History Traits and Conservation of the Vulnerable Souss Valley Tortoise in Arid Areas of West Central Morocco
}

\author{
Mohammed Znari and Nawal Hichami \\ Additional information is available at the end of the chapter
}

http://dx.doi.org/10.5772/intechopen.74855

\begin{abstract}
The Souss Valley tortoise, Testudo graeca soussensis, is endemic to the semi-arid and arid low quality habitats of west central Morocco. Populations of this area are among the bestinvestigated populations in western Mediterranean. The long-term conservation of these declining populations is of particular management concern for this endemic and threatened subspecies. Here we present a data review on biological and ecological aspects of this subspecies dealing with morphology, distribution range and climatic niche, habitat use, food habits, activity cycle, and thermal responses to arid hot conditions, post-hatching growth, sexual maturity, sexual dimorphism, breeding ecology and demographics. After an analysis of the major threats on populations, we proposed management actions required to improve the conservation outcomes for this endangered tortoise in arid areas of west central Morocco. Conservation and restoration potentials of the declining populations and their habitat are also described, including habitat restoration and a captive breeding program.
\end{abstract}

Keywords: Testudo graeca soussensis, arid environments, west-central Morocco, taxonomic status, biology, ecology, life history, threatened subspecies, conservation

\section{Introduction}

The Spur-thighed Mediterranean (or Greek/Moorish) tortoise, Testudo graeca L., 1758, is the unique land chelonian species in Northwest Africa north of the Sahara desert [1]. It occurs along an altitudinal gradient from coastal to mountainous (up to $2090 \mathrm{~m}$ a.s.l.) and pre-Saharan areas covering various habitats and bioclimates ranging from xeric $(116 \mathrm{~mm})$ to mesic $(1092 \mathrm{~mm})$ 
types [2]. Most research works on its distribution, ecology, and life history were carried out in Morocco (e.g., [3-10]). In North Africa, the species comprises five distinct subspecies, two of which are endemic to Morocco. Among these, the Souss Valley tortoise, T. graeca soussensis, occupies the southernmost part of the species distribution range in Southwestern Morocco. This mostly arid and highly populated area of the country constitutes one of the most touristic regions with an important land use for agriculture and livestock pasture. As reported in the 1970s and 1980s in Morocco [3], very few populations can still be considered abundant and free from human disturbance in this part of the country. Three main populations, especially one in the central Jbilet mountains, west-central Morocco, were intensively studied during the last two decades. The first ecological investigations on T. g. soussensis, were conducted in the Admine Forest located in the Souss Valley [5] where the subspecies was originally described by Pieh [11]. All these populations are threatened due to increasing impacts of human activities (i.e., urbanization, agriculture, overgrazing) and climate change resulting in frequent droughts. So, conservation and restoration of the subspecies and its habitat in west-central Morocco are required. In this chapter, we provide a summarized literature review on the biology, ecology and life history of this subspecies in west-central Morocco. We will also report on the main threats and conservation and restoration potentials of declining populations.

\section{Description of the subspecies}

The subspecies was originally described, based on morphology, as T. g. soussensis s sensu stricto by Pieh [11]. It can be distinguished from all known T. graeca subspecies tortoises by lacking thigh tubercles, a larger carapace size in adults, striped carapace markings, and markings that reach over the supporting parts of the plastron. With a few exceptions, the tortoises of the Souss Valley possess strikingly long pectoral scales. The length of the pectoral scales middle seam is usually more than $2 / 3$ of the length of the femoral scales middle seam. The Middle seam length of the pectoral scales in the majority of nominated form. In contrast, animals are less than $2 / 3$ of the femoral scale mid-suture length. The third vertebral is relative to adult carapace length male T. g. soussensis shorter than in male T. g. graeca Sensu stricto.

In their detailed morphometric study, Carretero et al. [6] questioned the validity of the taxon soussensis and pointed out that the diagnostic characteristics of the Souss Valley Tortoise provided by Pieh [11] could be confirmed only to a minor extent for the population of the Admine Forest, with only $23 \%$ of the examined specimens having no thigh spurs, only $7 \%$ exhibiting a divided anal scute, and the dimensions of the third vertebral scute not differing from those in specimens from the surroundings of Essaouira. In this conjunction, it needs to be noted though that the population from Essaouira, as well as the one from the Jbilets Mts, north of Marrakech, are nevertheless currently referred to the subspecies T. g. soussensis [6].

\subsection{Morphological variation and sexual dimorphism}

Using 41 carapace dimensions, Carretero et al. [6] found a significant morphological differentiation among tortoises from Admine Forest, Essaouira and Jbilet Mts, west-central Morocco 
(Figure 1). The population from Jbilet was the most differentiated (no overlap), those from Essaouira on the coast and from Admine showed limited overlap (5\%). Tortoises from Jbilet living under harsher conditions (low precipitation, high thermal amplitude, low plant cover) were smaller, lighter, more flattened and less dimorphic in shape than the others. This morphological variation contrasted with the non-significant genetic difference based on $12 \mathrm{~S}$ rRNA mtDNA among these three populations [12]. The observed morphological differences either have arisen very recently or can be attributed to phenotypic plasticity.

Indeed, Testudo g. soussensis exhibits high phenotypic plasticity in both size and shell shape $[6,13]$. In arid environments, in the central Jbilet, it is smaller, with a more flattened shape and a less marked sexual dimorphism than in the populations of the coastal zone of Essaouira and the Admine Forest in the Souss Valley. In the latter, tortoises have a body size (carapace length, CL) reaching maximum values of 184 and $226 \mathrm{~mm}$ corresponding to body weights of 1200 and $1996 \mathrm{~g}$, respectively in males and females [6, 13]. In addition, turtles in the coastal zone of Essaouira show a relatively pronounced melanism [6].

As T. g. graeca, T. g. soussensis are easily sexable; sexual size dimorphism with females larger than males, remained constant between sites. Sexual shape dimorphism is prominent in all populations, but the degree of dimorphism differs for some characters when corrected for size [6]. Females are distinguished by greater abdominal volume than males in order to increase the ability to carry eggs, while males develop larger openings in the carapace to increase their mobility in search of sexual partners. The males have a concave plastron, a more convex supracaudal, and a longer, thicker tail, whereas the females have a flat or slightly domed plastron and a flattened, rounded-edge supra-caudal and a short obtuse tail [3, 14]. Moreover, Ben Kaddour et al. [14] tested the hypothesis according to which in chelonians a reduction of the openings in the shell improves protection against predation but also constrains the abdominal volume and limits the space available to move the limbs. As expected, these authors found in the Souss Valley tortoises from central Jbilet, that the shell was shown to provide a larger


Figure 1. Results of the canonical analyses of morphometric variables (size-corrected) of Testudo graeca soussensis from West-central Morocco, performed separately for each sex (A: males and B: females) (modified after Carretero et al. [6]). 
abdominal volume relative to tortoise size in females than in males. In males, deep notches in the shell and a reduction of several plastron plates offer more freedom to the limbs and to the tail; these characteristics presumably enhance mating success.

\section{Taxonomy}

As for the other populations of Northwest Africa, all Moroccan populations were put together with T. g. graeca, excepting the questionable revalidation of T. whitei by Highfield and Martin [15] (see [17]) and the long-debated description of Furculachelys nabeulensis Highfield [16]. While the former was practically omitted from the scientific literature, the latter taxon was eventually confirmed as a subspecies of $T$. graeca [17] eventually confirmed. Using mitochondrial cytochrome $b$ gene and part of the adjacent tRNA-Thr gene, Fritz et al. [17] identified five distinct lineages within the western Mediterranean clade of T. graeca in North Africa. These lineages show a clear allo- or parapatric distribution from east Libya to west Morocco that matches well with previously morphologically defined subspecies (T. g. cyrenaica, T. g. graeca, T. g. soussensis, T. g. marokkensis, T. g. nabeulensis). Two of these are endemic to Morocco: T. g. marokkensis, and T. g. soussensis (Figure 2). As above-mentioned, this latter was described for the first time as a new subspecies by Pieh [11] on the basis of external morphology from the type locality near Agadir city $\left(30^{\circ} 28^{\prime} \mathrm{N}, 9^{\circ} 55^{\prime} \mathrm{W}\right)$ in the lower Souss valley. The Souss valley is the alluvial basin of the Oued (river) Souss located in mid-southern Morocco, southwest of the Western High Atlas range and separated from the Sahara desert by AntiAtlas Mountains.

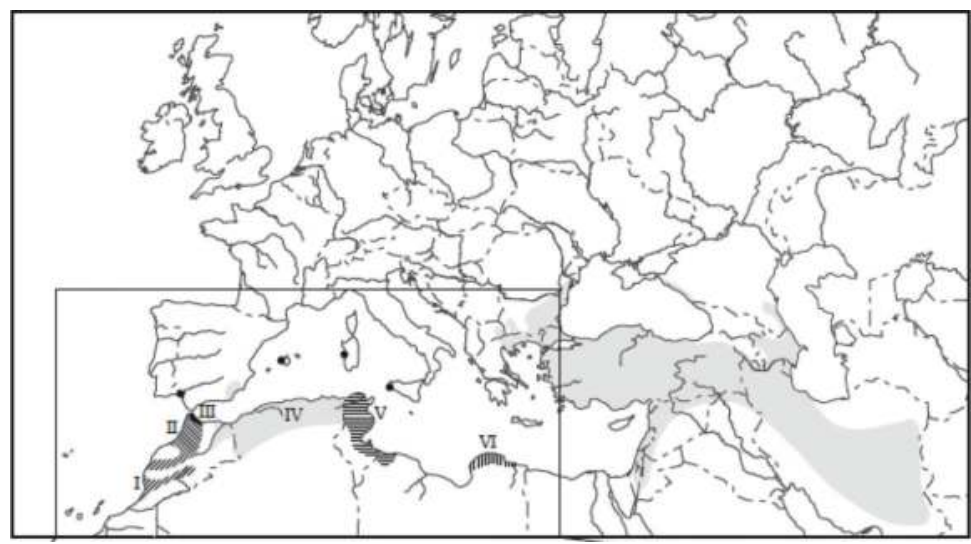

Figure 2. Geographic distribution of Testudo graeca subspecies currently recognized in the western Mediterranean: I-Testudo graeca soussensis Pieh, 2001; II-T. g. marokkensis Pieh and Perälä, 2004; III-T. g. Lamberti Pieh and Perälä, 2004; IV-T. g. graeca Linnaeus, 1758; V-T. g. nabeulensis (Highfield, 1990); VI-T. g. cyrénaïque Pieh and Perälä, 2002 (modified according to Fritz et al. [17]). 


\section{Current distribution and quaternary range dynamics}

The distribution range of $T$. g. soussensis was restricted to the Souss valley and the few "records" from the surroundings of Ouarzazate $[18,19]$ likely to be referable to this subspecies as well [11]. Few years later, Pieh and Perälä [20] extended the distribution of this subspecies to the southern areas of the Central Meseta, i.e., to the northern parts of the High Atlas and the adjacent forelands (Figure 3).

Testudo g. soussensis occurs in three areas of west-central Morocco: the Souss Valley throughout the coastal line southwest to Anti-Atlas, semi-arid and arid lands north of High Atlas to the mid-Atlantic coastal line around Essaouira, and the area in the vicinity of Ouarzazate. According to the maps of Lambert [4] and the distribution map of Bons and Geniez [19], there is an occurrence gap for T. graeca in Morocco range of the ridges of the High Atlas and the Atlantic coast near Tamanar (see Lambert [3]). It occurs along an altitudinal gradient from $5 \mathrm{~m}$ on the Atlantic coast (Essaouira area) to $1600 \mathrm{~m}$ in the Anti-Atlas range (W of Aoulouz), under semi-arid to pre-Saharan bioclimates. South of the Anti-Atlas and High Atlas, the probability of occurrence drops considerably due to the strong aridity gradient; no tortoises have been recorded where annual rainfall is lower than $139 \mathrm{~mm}$, recorded $40 \mathrm{~km}$ south-west of Tiznit in the southwest coast region of Morocco [4].

Following a purportedly tortoise-free zone (from the Atlantic coast around Safi via the Chemaia Plateau east to where the Middle and High Atlas merge [20], the northern parts of

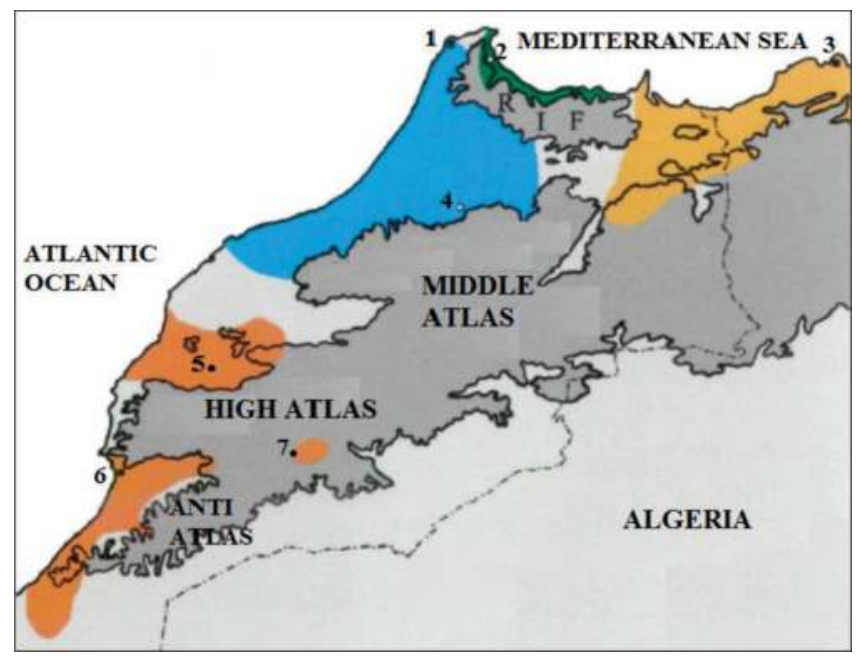

Figure 3. Distribution of Testudo graeca soussensis (sensu stricto and sensu lato) in western Morocco (orange); Testudo graeca marokkensis (light blue + Testudo graeca lamberti (green)) in northwestern Morocco, and Testudo graeca graeca in northeastern Morocco (ocher). The numbers refer to the cities Tangiers (1), Tetuan (2), Oran (Algeria [3]), Oulmes (4), Marrakech (5), Agadir (6) and Ouarzazate (7) (modified after Pieh and Perälä [20]). 




Figure 4. Schematic representation of the post-glacial range dynamics of the five subspecies of T. graeca in north Africa based on ENMs: T. g. cyrenaica (green), T. g. nabeulensis (yellow), T. g. graeca (red), T. g. marokkensis (orange) and T. g. soussensis (blue) (After Anadón et al. [21]).

the High Atlas are where the distribution range of $T . g$. soussensis sensu lato begins. It is once more separated by a tortoise-free zone along the western slopes of the High Atlas from that of the actual Souss Valley tortoises. Their occurrence extends from the Souss Valley and along the Atlantic coast to the level of the southernmost foothills of the Anti-Atlas.

Using ecological niche modeling, Anadón et al. [21] showed a clear niche differentiation among the five subspecies of T. graeca in North Africa, in response to past climate changes, particularly in relation to rainfall, covering a range from semiarid to humid. Since the Last Glacial Maxima, the range of T. g. soussensis has shifted northwards while those of the other subspecies have either expanded (T. g. graeca), contracted (T. g. marokkensis) or remained stable (T. g. cyrenaica and T. g. nabeulensis) (Figure 4). Molecular data supported this biogeographic dynamics that would have been strongly affected by precipitation changes during glacial periods. Rainfall plays a primary role in shaping the distribution of T. graeca $[2,4]$. Rainfall in the coldest quarter (i.e., winter) is the strongest limiting factor for the five subspecies, supporting the key role of available primary productivity in spring for the energy budget and the population dynamics of the species. While T. g. marokkensis, T. g. nabeulensis and T. g. cyrenaica were qualified as 'humid' subspecies with a maximal probability of occurrence at a rainfall range of $800-1200 \mathrm{~mm}, T$. g. graeca and T. g. soussensis, were defined as semiarid taxa since their probability of presence increases rapidly slightly below 200 and presents an optimum in semiarid conditions (200-400 mm). However, whereas T. g. graeca can be described as 'semiarid but generalist' taxa, able to cope with humid conditions, T. $g$. soussensis is a 'strict semiarid' taxon since the probability of presence plums between 300 and $400 \mathrm{~mm}$.

\section{Ecology and behavior}

\subsection{Habitat}

Comparatively to the other North African subspecies, T. g. soussensis occurs in lower quality habitats with low rainfall and high thermal seasonality in semi-arid and arid zones of the central-western and southeastern parts of the Morocco [2]. Within the Admine Forest, in the 
Souss Valley, there are pockets of agricultural land surrounding the villages, which are predominantly composed of small fields of $0.1-2$ ha that are surrounded by thorny hedges. The most widespread hedging material is Opuntia ficus indica, a cactus species introduced from the Americas, whilst the endemic Jujube species Ziziphus lotus is the next most abundant. Both species provide the major present day habitat for T. g. soussensis: O.f. indica has created an important new habitat providing good protection from predators and humans, a food source, and good nesting, basking, aestivation and scrape sites (the use of individual sites depending on the aspect of the bank and season of the year). It is interesting to note that this introduced cactus, much maligned in Australia for its effect upon indigenous species, should now be such an important refuge for tortoises in Morocco.

In the arid-steppe lands of the Haouz plain and central Jbilet Mountains, tortoises were found to depend on the occurrence of large (taller than $1.25 \mathrm{~m}$ ) and relatively abundant Jujube bushes (Z. lotus) to escape lethal overheating during the hot and dry periods [8]. In the absence of such relatively large bushes, the tortoises are under serious threat of lethal overheating, indeed ambient and estimated body temperatures largely exceeded $40^{\circ} \mathrm{C}$ for prolonged periods in all other microhabitats. Therefore, the short-term (hours in summer), survival of the tortoises depends closely on the presence of relatively large bushes; all individuals use this specific microhabitat intensively all year round, and exclusively in summer $[5,8]$.

\subsubsection{Habitat use}

The Souss tortoises do not appear most of the time in places where the vegetation overtops the height of cereal fields almost exclusively in or near Jujube bushes (Z. lotus). These largely impenetrable thorny bushes provide shelter for larger animals, and in their shadows grow herbaceous plants that feed the tortoises. Likewise, tortoises were found on stone wall field boundaries where wind and evaporation protection allow a rich vegetation flourishing. They are also encountered on the mid-Atlantic coastal area in sand dunes and within Argan forests, among scattered shrubs around cultivated fields $[8,9]$.

\subsubsection{Tortoise scrapes and burrows}

In the Souss Valley, tortoises use scrapes and burrows to avoid the mid-day heat, for shelter at night and for prolonged aestivation periods. These scrapes and burrows vary considerably in opening size and depth. If some relatively small ones can be produced by tortoises, others clearly surpass their digging abilities and shows signs of previous occupation by mammals such as honey badger (Mellivora capensis) and Geoffroy's ground squirrel (Xerus erythropus). Shallow scrapes are often observed at the base of O.f. indica hedging, where the presence of roots stabilizes the otherwise loose and structureless sandy soil. Larger burrows are also found in these hedges, but are more frequently located in fossilized sand dunes and in the banks of dry rivers. Burrow depth at these sites varied from $40 \mathrm{~cm}$ to more than $1.5 \mathrm{~m}$. Several aestivating tortoises were located in a series of deep burrows in a fossil sand dune. Similarly, in the arid-steppes on the central Jbilet mountains, shallow scrapes were encountered under Jujube/Acacia bushes; tortoises can also shelter in large entrances of Bibron's Agama (Agama impalearis) burrows, under stones (shales) or within under-road/rail tunnels [5, 8, 9, 22]. 
During the hottest and driest periods (late May to early September) in the central Jbilet mountains [9], radio-tracked tortoises were all found sheltered for a long period under large bushes. Most of them ( $90 \%)$ were immobile and partly buried. During cooler periods, notably spring and autumn, the tortoises were more frequently under the bushes, but moving regularly [9]. Tortoises used mostly jujube bushes that were higher than $3 \mathrm{~m}$, and in few cases, oleanders (Nerium oleander) taller than $2 \mathrm{~m}$. They were rarely observed in the open, moving relatively rapidly between shelters. Average home ranges (minimum convex polygon) represented less than 0.3 ha (range: $0.4-8.9 \mathrm{ha}$ ). The tortoises travelled $2.5 \mathrm{~km}$ on average (range: $1.3-3.9 \mathrm{~m}$ ). Males travel over longer distances than females ( 3.2 versus $1.9 \mathrm{~km}$ ) correlatively to their larger mean home range $\left(4.7\right.$ versus $\left.0.7 \mathrm{~m}^{2}\right)[8,9]$.

\subsection{Activity cycle and time-activity budget}

\subsubsection{Annual activity}

According to Bayley and Highfield [5], brumation (i.e., a hibernation-like state that coldblooded animals utilize during very cold weather) does not occur in the Admine Forest, Souss Valley, where average monthly mean temperatures in the coolest part of the year (December and January) do not fall below 14.8 and $13.6^{\circ} \mathrm{C}$ respectively. Average daily temperatures in winter are typically $23.8^{\circ} \mathrm{C}$ in November, $20.8^{\circ} \mathrm{C}$ in December and $31.1^{\circ} \mathrm{C}$ in January. Air temperatures at sites where active tortoises were observed in mid-December 1994 ranged from 24 to $27^{\circ} \mathrm{C}$ between 10.00 and $14.00 \mathrm{~h}$. The temperature recorded in scrapes and shallow burrows occupied by tortoises was typically $24-26^{\circ} \mathrm{C}$ and the relative humidity there ranged from 48 to $60 \%$ compared to $20 \%$ or less in exposed areas.

Aestivation typically begins in June and ends in September. The precise timing is affected by prevailing temperature and, especially, by precipitation. In drought years aestivation may be considerably extended. Tortoises are invariably aestivating during July and August where average mean monthly temperatures are 22.2 and $22.5^{\circ} \mathrm{C}$, respectively. Peak daily temperatures during these months can exceed $48^{\circ} \mathrm{C}[5,8,9]$.

Utilizing automatic acceleration recorders, Lagarde et al. [8] characterized and monitored long time behavioral sequences of free-ranging tortoises in central Jbilet Mountains. They recorded and compared the activity budget of males and females under natural conditions during the spring (Figure 5). Tortoises monitored during 24 consecutive hours, remained inactive at night. The average daily activity time was $7650 \mathrm{~min}$. Under unfavorable climatic conditions (strong wind combined with an ambient temperature $<15^{\circ} \mathrm{C}$ ), some individuals were mostly inactive with a total activity of less than $5 \mathrm{~min} /$ day and few others remained motionless. The duration of the total activity time in active animals was on average less than $2 \mathrm{~h} /$ day. The mean daily active time (including the inactive animals) was significantly longer in females compared to males (9455 min versus $6039 \mathrm{~min}$, respectively) [8, 9].

The tortoises devoted most of their activity time to walking and foraging behaviors (40 and $36 \%$ of the total activity time, respectively). Sexual and fighting behaviors were very infrequent representing less than $2 \%$ of the total activity time, in both sexes. Burrowing and walking behaviors lasted respectively less than 25 and 40 min per day without difference between sexes. Females spent more time foraging than males, but these were more frequently immobile (Table 1) [9]. 


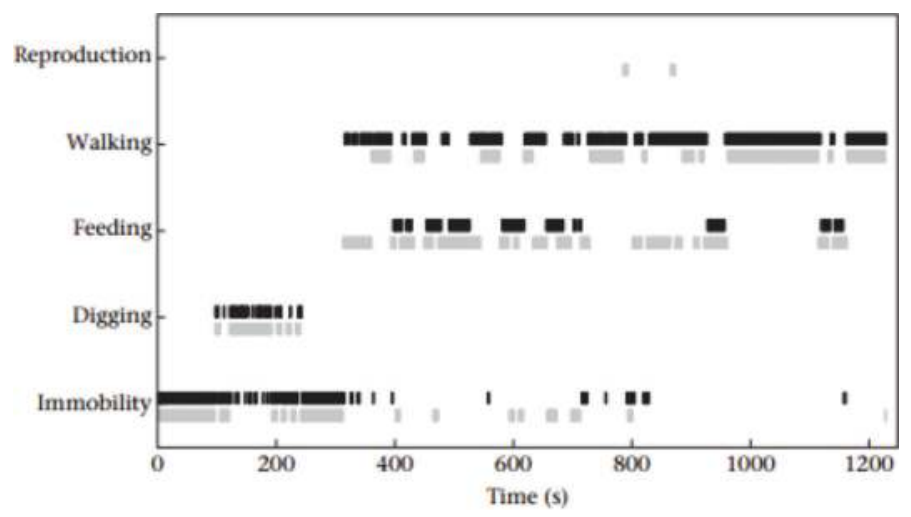

Figure 5. Observed (black bars) and reconstituted (grey bars) behaviors of Testudo graeca soussensis in the spring, in the Central Jbilets, Morocco (modified after Ben Kaddour et al., 2008).

\begin{tabular}{|c|c|c|c|c|c|c|}
\hline \multirow[b]{2}{*}{ Behaviour } & \multicolumn{2}{|c|}{ Males $(N=24)$} & \multicolumn{2}{|c|}{ Females $(N=24)$} & \multicolumn{2}{|c|}{$\begin{array}{l}\text { Comparisons between } \\
\text { the sexes (Mann-Whitney) }\end{array}$} \\
\hline & Duration (min) & $\%$ & Duration (min) & $\%$ & $u$ & $P$ \\
\hline Immobility & $1360.1 \pm 49.3$ & 94.8 & $1322.0 \pm 60.7$ & 92.4 & 183 & 0.03 \\
\hline Walking & $33.2+24.6$ & 2.3 & $45.8 \pm 29.8$ & 3.2 & 216 & 0.14 \\
\hline Feeding & $26.2 \pm 18.4$ & 1.5 & $46.3 \pm 30.5$ & 2.6 & 169 & 0.01 \\
\hline Digging & $19.5 \pm 14.7$ & 1.4 & $24.1 \pm 16.8$ & 1.7 & 245 & 0.38 \\
\hline Reproductive & $1.0 \pm 1.5$ & 0.1 & $1.8 \pm 4.0$ & 0.1 & 287 & 0.99 \\
\hline
\end{tabular}

Table 1. Activity budget of free-ranging male and female Testudo graeca soussensis in spring, in the Central Jbilets, westcentral Morocco (Ben Kaddour et al., 2008).

\subsection{Thermal ecology}

Like most animals, the Souss Valley tortoise must navigate between microhabitats to find essential feeding resources and thermal refuges. Combining radio-tracking of free-ranging individuals, microhabitat temperature monitoring and transects in a range of habitats, in central Jbilet Mts, Lagarde et al. [8] found tortoises to depend on the occurrence of large and relatively abundant Jujube bushes (Z. lotus) to escape lethal overheating (Figure 6).

As suggested by the null models, both the air temperature and the body temperature $(\mathrm{Tb})$ of tortoises do not reach $40^{\circ} \mathrm{C}$ during cool/cloudy days. During sunny days, the tortoises are exposed to potential overheating $\left(\mathrm{Tb}>40^{\circ} \mathrm{C}\right)$ and solar radiation for a minimum of $1 \mathrm{~h}$. Large bushes provide thermally buffered conditions while other habitats are potentially risky. Females are less subject to overheating, owing to their much larger size (mean adult body mass: 1.0 versus $0.46 \mathrm{~kg}$ ) [8,9].

In central Jbilet Mts, during hot periods, the tortoises could safely travel around $900 \mathrm{~m}$ in the open in an average time of nearly $3 \mathrm{~h}$. However, these values vary according to the time of emergence. The estimated safe distance rapidly decreased from 8:00 to 13:00, and then tended to stabilize after 15:30; reflecting the reducing intensity of solar radiation in the afternoon and 


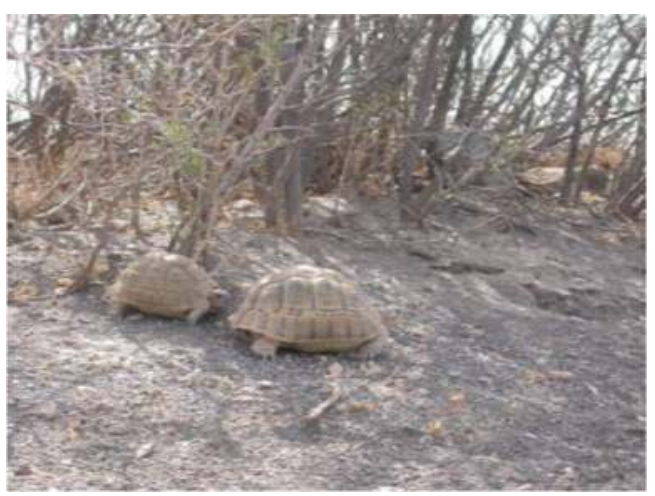

Figure 6. A pair of tortoises (left: male; right: female) active in the shade of a Jujube bush (Zizyphus lotus) in the central Jbilet Mountains, west-central Morocco (photo T. Louzizi).

concomitant decreasing overheating risk. However, individuals must shelter before night; tortoises leaving the bushes after 17:00 could not travel far as the activity stops around 19:0019:30. In the afternoon the body temperature of the sheltered tortoises was already elevated, thereby improving locomotors performance compared to individuals leaving their refuge in the morning and that must bask in the sun prior movements (night temperatures were often low), but this also accelerated overheating risk $[8,9]$.

The estimated maximal $\mathrm{Tb}$ (recorded between 16:00 and 19:36) of the free-ranging tortoises, walking in the open was $34.7^{\circ} \mathrm{C}$ for males and $33.6^{\circ} \mathrm{C}$ for females. Males exhibited higher maximum $\mathrm{Tb}$ than females $\left(33.1 \pm 0.8^{\circ} \mathrm{C}\right.$ versus $\left.31.3 \pm 0.7^{\circ} \mathrm{C}\right)$. The large body size of the females provided a buffering advantage and they were able to travel farther than males. For example, during the hottest periods (at 11:00), the estimated theoretical maximum distance, a tortoise can move is $494 \mathrm{~m}$ for males and $673 \mathrm{~m}$ for females [8, 9].

\subsection{Food habits}

The dietary constituents of the species in Admine forest (Souss Valley), included, in addition to various wild plant species, several cultivated species [5]. In this area, displacement of tortoises from the Argan forest because of overgrazing, loss of ground cover and drought has led to their concentration along the margins of cultivated fields. In these situations a high proportion of their diet now consists of O.f. indica cacti and agricultural crops (French and broad beans, lucerne, potato leaves, tomatoes, lettuce, zucchini, cauliflower and cabbage). In the Jbilet Mts, T. g. soussensis fed only on a small proportion of the available plant species during the spring season, but at the same time did not discriminate against species that would be toxic to mammals [7]. The diet composition, obtained by fecal analysis and compared to plant assemblages seems rather a specialist herbivore. The five main plant species found in fecal samples (Leontodon saxatilis (Asteraceae); Malva parviflora (Malvaceae); Astragalus cruciatus, Medicago hispida and Lotus arenarius (Fabaceae)) represent $70 \%$ of the identified material and were highly preferred whereas several other plant species, common in the field (e.g., Eryngium ilicifolium (Ombellifereae); Emex spinosus (Polygonaceae); Spergula flaccida Caryophyllaceae)) 
were actively avoided. Fabaceae made up $27 \%$ of the diet and may be important forbs in the diet of terrestrial tortoise owing to their high nutritional value. The diet composition of $T$. $g$. soussensis suggests that diet overlap may occur between domestic ungulates and tortoises in overgrazed landscape and could generate a competition context. However, T. g. soussensis seems to focus its foraging effort mostly under the spiny Jujube shrubs where the impact of overgrazing is strongly attenuated $[7,22]$.

The spring specific richness of plants in the Jbilet habitat was reduced during drier years (2011 and 2012) compared to that reported in a previous above-normal rainfall year [22] (44 and 27 versus 88 plant species). The dry plant biomass density differed greatly between under and out of the Jujube. The mean plant species richness and the total dry biomass density were higher in under than in out Jujube. Tortoises tended to consume only about 5-6 and almost the same species, out of all the available annual forbs and grasses. The total number of plant species that were counted as being within the top 5 for all tortoises included more than 8-10 species. Many other species, abundant in the habitat, were rather avoided. It was suggested that the few herbaceous plants that represented $\sim 90 \%$ of tortoise diet, might be important in sustaining tortoise populations during droughts. These results underline the tortoises' vulnerability to global change on the availability of their preferred food plants [22].

The diet composition showed significant differences among seasons, either qualitatively or quantitatively [22]. The spring diet was more diverse with 16 plant species consumed against only 5 and 7 species in summer and autumn-winter respectively, with 5 shared species (Cynodon dactylon, Salvia aegyptiaca, Leontodon saxatilis, Lotus arenarius and Medicago hispida) during the all seasons.

\subsection{Growth and sexual maturity}

Both male and female tortoises from the central Jbilet Mountains, the Admine Forest, and near Essaouira, grew relatively quickly for 10-12 year in all three populations, after which their growth rates decreased markedly. Females in all three populations had greater asymptotic sizes than males, and CL and log mass differed significantly between sexes by age 9 year for the three populations, except for log mass of tortoises from Essaouira, which differed by age 6 . Mean CLs and log masses were significantly greater in Admine and Essaouira tortoises than in tortoises from Jbilet [13].

The growth period T, equivalent to the age at which $90 \%$ of the asymptotic CL is reached, was delayed by approximately 3 year in females relative to males in tortoises from Jbilet (males 14.9 year; females 11.8 year) and Admine (males 12.0 year; females 9.0 year), but not in Essaouira (males 11.4 year; females 11.8 year). Growth was relatively fast for the first 7-10 year of life for tortoises in all three populations whether based on CL or log mass. Growth decreased rapidly after about 10-12 year. Based on calculated CL and calculated mass, tortoises from Admine became larger than tortoises from Jbilet between 3 and 6 year and tortoises from Essaouira exceeded the size of tortoises from Jbilet between 1 and 3 year. A significant sexual size dimorphism occurred by 9 year of age for the three populations based on calculated CL. Based on calculated mass, male and female tortoises from Essaouira diverged in size by 6 year of age, whereas there was no divergence between sexes in mass until 9 year of age for tortoises from Jbilet and Admine. Growth patterns differ significantly 
between sexes at an age below 8 years, but not between 1 and 5 years of age. From an age of 5 years, a decrease in growth rates of males is observed, whereas those in females increased until 6-7 years of age and then strongly decrease afterward. There was no significant difference in growth patterns between sexes after the age of 8 years [13].

The age at sexual maturity, estimated using large carapace growth annuli, varies from 6 to 9 years for males and from 8 to 11 years for females (7 versus 9 years in average) [13, 22]. The males reached their sexual maturity at a lower mean minimal size $(90.7 \pm 10 \mathrm{~mm}$, range: 91.4-131.4 mm) than females (146.2 \pm 16.5 , range: $71.8-114.6 \mathrm{~mm})$. More than $60 \%$ of males attained the sexual maturity between 6 and 7 years with a carapace length of 100-120 mm, while around $60 \%$ of females are mature between 9 and 10 years with a carapace length ranging from 140 to $170 \mathrm{~mm}$. The estimated minimal size at maturity, based on the sexual behaviors observed in the wild (courtship, mating) is 104.8 and $152 \mathrm{~mm}$, respectively for males and females [13].

Sexual size dimorphism index (SDI) calculated by dividing the size (mean CL) of the females by the size males and subtracting one [23], is almost constant in the three populations and averaged 0.17. Mass of all tortoises (all age classes and sexes combined) from the three populations is highly correlated to CL.

\subsection{Reproductive ecology}

Only limited data are available on breeding cycle and clutch characteristics in T. g. soussensis in west-central Morocco $[5,10]$.

Mating activity in the Souss Valley tortoises from Admine Forest occurs bimodally in the early spring and in September, immediately following emergence from aestivation. In semi-captive Souss Valley tortoises from central Jbilet Mts, courtship and mating activities in occurred in early spring, from March to early May, and again in mid-Autumn, for a shorter period from late October to early November [10].

Serreau et al. [25] reported low plasma testosterone levels that were associated with mating periods in spring and to a lesser extent in autumn whereas two peaks, one in winter and one in summer, corresponded to periods of inactivity. Strong contrasts in plasma hormone levels induced by experimental treatments did not result in changes in activity budget or space use, both in the short-term or more than one month after the beginning of the hormonal treatment. It was concluded that testosterone levels did not affect directly behavioral activity in T. g. soussensis, either immediately or after a one-month time delay.

The egg-laying season occurs in May and June in the Souss Valley [5] and from late May to early July in central Jbilet Mts [10]. Nesting sites in the Souss Valley are usually located in sandy banks on the periphery of cultivated fields and at the base of O.f. indica hedging [5].

Mean clutch size in T. g. soussensis varies from 3.44 to 3.80 eggs with a range of 1-7 within a clutch $[5,10]$. As indicated by their shape index, eggs in T. graeca soussensis from central Jbilet are rather elliptical-oval in shape. However, sub-spherical eggs with a shape index close to 1 were found in Admine Forest, Souss Valley, Morocco [5] and North Essaouira, west-central 
Morocco (unpublished data) (Table 2). The elongated eggs in T. g. soussensis from Jbilet may be attributed to their smaller body size and more flattened carapace compared to those from other populations of west-central Morocco [6]. The mean relative egg mass and relative clutch mass are $1.70 \pm 0.28 \%$ and $4.06 \pm 1.32 \%$, respectively. No egg variable was significantly correlated with the female body size (carapace length and body weight) [10].

Average incubation duration at $31^{\circ} \mathrm{C}$ in $T$. g. soussensis in Jbilet, was 70 days ranging from 62 to 78 days [10]. Krüger [24] found comparable values of 72 and 81 days at $28^{\circ} \mathrm{C}(6 \mathrm{~h})$ to $33^{\circ} \mathrm{C}$ $(18 \mathrm{~h})$ in two artificially incubated clutches from semi-captive females from Southwestern Morocco. On the other hand, in a successful near-natural incubation experiment in Germany, at temperatures varying from 15 to $41^{\circ} \mathrm{C}$, the incubation duration was much longer, ranging from 82 to 140 days [24].

Emergence occurs in September. Mean hatchling body mass and carapace length in central Jbilet were $12.8 \mathrm{~g}$ and $35.7 \mathrm{~mm}$, respectively (Figure 7). In semi-captive T. g. soussensis, Krüger [24] reported a lower mean hatching body mass of $11.7 \mathrm{~g}$. The carapace in hatchlings is subcircular and more domed compared to that of adults with a more elongated and flattened carapace. The more domed shell of the hatchlings would reduce surface area relative to volume, probably to compensate for high evaporative water loss from the leathery soft shell compared to the hardened thick carapace of adults [10].

\subsection{Population structure and dynamics}

In the early 1990s, the Admine population showed a highly unbalanced sex-ratio of 2.25 (69.2\% of males) and only $27.6 \%$ of immature individuals. A predominance of young males was encountered with $66 \%$ of the males or $41.4 \%$ of the total population. These males were aged of $11-25$ years compared with $75 \%$ of the females or $20.7 \%$ of the total population [5].

In spring-summer 2001, Znari et al. [13] reported significant differences in size-structure, but not age-structure among three populations (the central Jbilet Mts, Admine forest and Near Essaouira) of west-central Morocco (Figure 8). No tortoises older than 16-18 years were found at any site. Most populations of tortoises suffered over-collecting for the tourist trade

\begin{tabular}{|c|c|c|c|c|c|c|c|}
\hline Origin & $\begin{array}{l}\text { Chutch } \\
\text { number }\end{array}$ & Chutch sise & Egg mass (g) & $\begin{array}{l}\text { Egg length } \\
\text { (mm) }\end{array}$ & $\begin{array}{c}\text { Egg vidth } \\
\text { (mm) }\end{array}$ & $\begin{array}{l}\text { Shape } \\
\text { index }\end{array}$ & Reference \\
\hline Admin forest & - & $(5-7)$ & - & 30 & 27.5 & 1.09 & Bayley be Highfield 1996 \\
\hline Southern Essaouina & 10 & $3.5(2-5)$ & - & - & - & - & Barje et al., (2005) \\
\hline Southwest Morocco & 2 & $(5-6)$ & - & - & - & - & Krrïger (2007) \\
\hline Northem Eesa outra & 7 & $3.6(1-5)$ & $\begin{array}{c}17.28 \\
(14.30-18.50)\end{array}$ & $\begin{array}{c}32.06 \\
(29.70-35.40)\end{array}$ & $\begin{array}{c}28.95 \\
(27.80-30.20)\end{array}$ & 1.11 & Unpubliehed data \\
\hline Jbilet Mts, Morocco & 6 & $3.44(1-5)$ & $\begin{array}{c}19.34 \\
(16.8-23.6)\end{array}$ & $\begin{array}{c}36.24 \\
(34.3-42.5)\end{array}$ & $\begin{array}{c}29.99 \\
(28-31.5)\end{array}$ & 1.21 & Hichami etal, (2016) \\
\hline
\end{tabular}

Table 2. Clutch size and egg characteristics of Testudo graeca soussensis from different areas of west-central Morocco. Values are means with their standard deviations and/or ranges (between brackets) when available (modified after Hichami et al. [10]). 


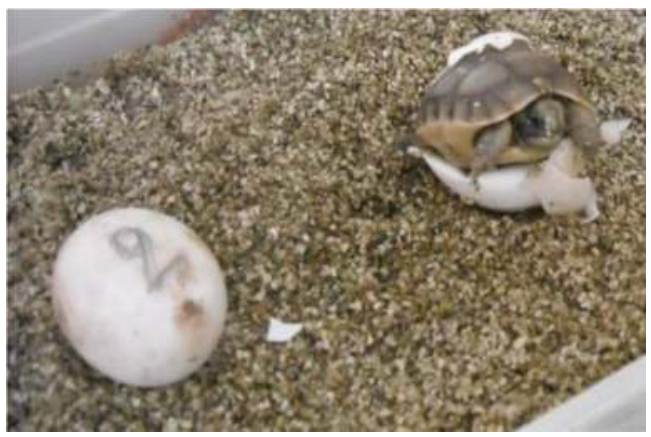

Figure 7. An unhatched egg and a newly-hatched Souss valley tortoise (Testudo graeca soussensis) obtained under artificial incubation at $31^{\circ} \mathrm{C}$ (photo M. Znari).

in the past, and some collecting still continues, which probably explains the lack of older tortoises. Juveniles (age $<7$ year) represented 21 and 23\% of the population for Jbilet and Essaouira, respectively, but only $14 \%$ for Admine. Young adults (7-12 year) were less frequently encountered in Essaouira (47\%) than in Jbilet (61\%) and Admine (68\%). Conversely adults older than 12 year were more frequently encountered in Essaouira (28\%) than in Jbilet and Admine (18\% each). Sex-ratios were not significantly different from 1 (or 1:1) for both Jbilet and Essaouira populations, whereas for Admine, the sex-ratio was male biased (1.69 or 1:0.59) [13].

In the central Jbilet Mts, the apparent age-structure of tortoises captured during the activity season (mid-February to late May 2003) was characterized by the lack of juveniles aged from 2 to 5 years old. Most of the individuals (74\%) were larger than $100 \mathrm{~mm}$ in carapace length and $72 \%$ more than 7 years old [14]. The age distribution was not significantly different between males and females [22]. In spring 2012, the apparent frequency distribution of the captured tortoises was characterized by the scarcity of juveniles aged 1-5 years, which accounted only for $5 \%$ of the total population. Most individuals observed (95\%) were adults with a carapace length $>100 \mathrm{~mm}$. The age-class structure among male and female subpopulations was significantly different. The adult sex ratio was male-biased, estimated to 1.2 (55\% of males) [22] and 1.57 (61\% of males), respectively in spring 2003 [7] and 2012 [22]. Females were significantly distributed in larger classes, the largest adult female and male reached the respective sizes of 190 and $148 \mathrm{~mm}$.

The estimated population size in spring 2003 was $192 \pm 20$ corresponding to a 5.9 ind./ha population density [7]. Male and female subpopulation size estimates were respectively $121 \pm 19$ and $100 \pm 18$. In spring 2012, the estimated population size declined to an average of $88 \pm 4$ ind. leading to a mean population density of 2.7 ind./ha [22]. This indicates a considerable decline of $54 \%$ in less than 10 years. Mean annual survival rates for adult male and female tortoises, estimated during the period of 2008-2012, were respectively $0.86 \pm 0.12$ (confidence interval range: $0.743-0.978$ ) and $0.81 \pm 0.18$ (confidence interval range: $0.634-0.987)$ [22]. 

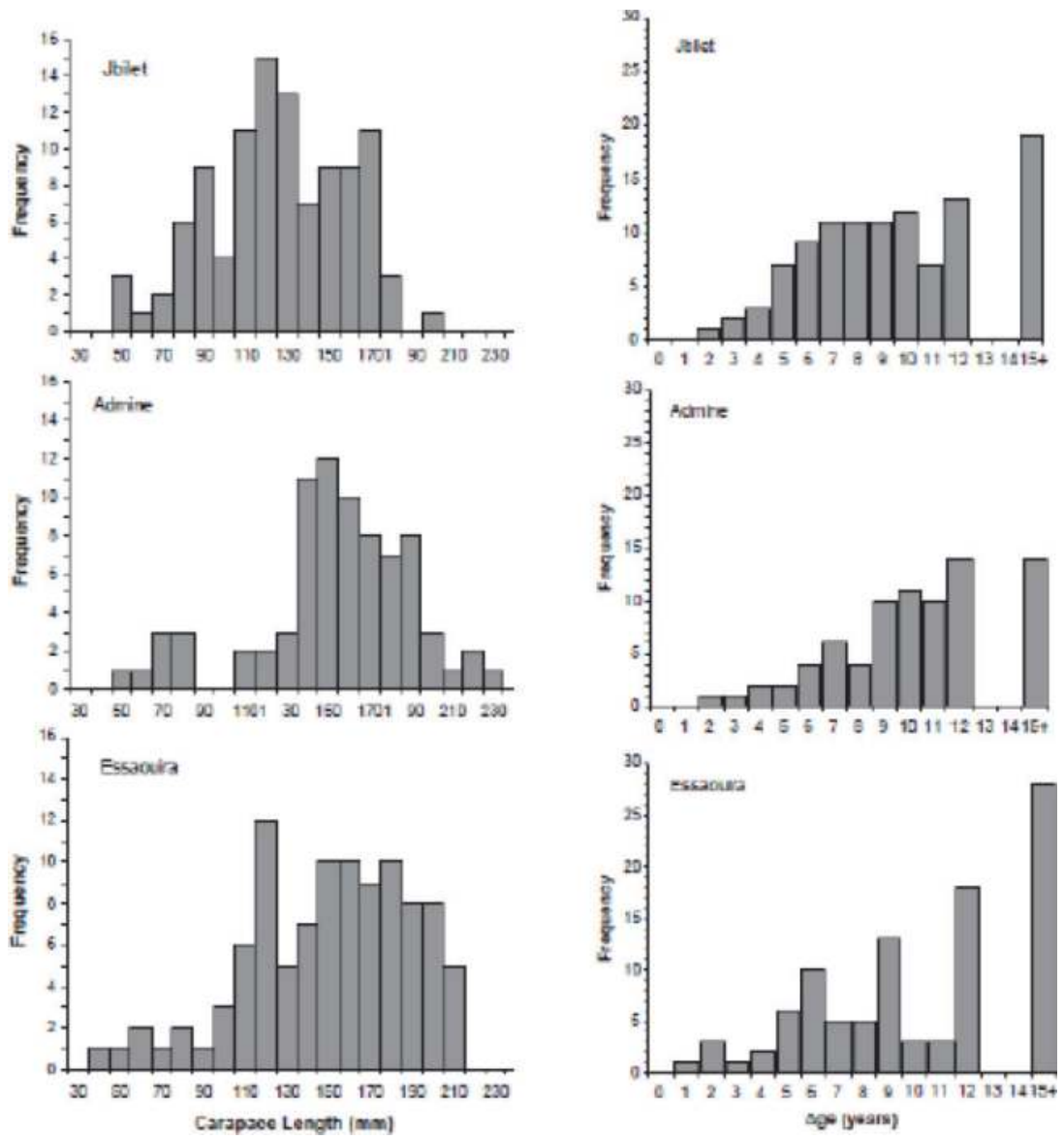

Figure 8. Population structure based on carapace length (left) and age (right) of Testudo graeca soussensis from the Jbilet Mountains (top), Admine Forest (middle), and near Essaouira (bottom), Morocco.

\subsection{Predation and parasites}

\subsubsection{Predation}

Predation, while almost exclusively a threat to eggs, hatchlings, and small juvenile tortoises, continues to be an ever-present threat. Nevertheless, in hatchlings, and to a lesser extent, in juveniles the shell is soft and/or not solid enough to resist to many predators such as canids, or birds for example (e.g., [26, 27]). In an open landscape, the predation on these fragile tortoises can be severe; sometimes leaving strong marks on the population dynamics [27]. In the Admine forest (Souss Valley), common predators of hatchlings observed in this region include hedgehogs, rats and birds of prey [5]. In an Argan (Argania spinosa) Forest, south of Essaouira, hatchlings of T. g. soussensis were found impaled by the Grey Shrike Lanius 
meridionalis, on spiny shrubs in both Essaouira region $\left(31^{\circ} 23 \mathrm{~N}, 9^{\circ} 42 \mathrm{~W}\right)$ and the central Jbilet, near Marrakech [28]. All the impaled tortoises were located on scattered shrubs around the cultivated zones that possess abundant food resources and a relatively deep and loose soil; they may be attractive for females before laying. The mean carapace length in Essaouira was $28 \pm 3$ (range: $25-35 \mathrm{~mm}$ ). Such a cryptic behavior may well be extremely pronounced in the soft hatchlings. Perhaps that the shrikes prospect areas where the concentration of juveniles is potentially high, typically around laying sites after emergence. The unlucky victims had not been discovered right in an Argan forest, though, but rather on solitary trees growing in areas used for agriculture.

\subsubsection{Parasitism}

Most of tortoises in central Jbilet Mts are infested, at various degrees, with ticks (with up to 10 ticks on the same tortoise) [21]. The infesting ticks, mostly Hyalomma aegyptium, the Family Ixodidae, were found to carry various microorganisms [29]. According to these authors, and in addition to various specific infections, the ticks can act as mechanical or biological vectors of different bacterial pathogens in both tortoises and humans. The most important bacteria, are Salmonella species bacteria that were found in almost $90 \%$ of tortoises from central Jbilet Mts [30]. In terrestrial chelonians, Salmonella species are considered part of the intestinal flora, and do not cause any clinical signs. However, in immune-compromised animals, they may cause salmonellosis, an important reptilian zoonosis [30].

\section{Threats and conservation status}

As the other Mediterranean populations, North African populations of T. graeca are considered as threatened, even though the true conservation status is not well known. In fact, these populations are declining in the majority of their habitats, particularly in Morocco and northwestern Algeria [31]. Since the 1980s, Lambert [3] had stated that only a few Moroccan populations of T. graeca can be considered abundant and free from human disturbance. Population decline is partly due to extensive collection for the pet and tortoise-derived souvenir trade to tourists [5], and also due to habitat losses resulting from human population growth and climate change which have promoted desertification, urbanization and the intensification of agriculture [5]. Because of this, T. g. soussensis is officially considered to be globally threatened, and is listed in Annex II of the Washington Convention and considered 'vulnerable' by the CITES. Surprisingly, in a recent national Red List assessment of Morocco's herpetofauna, Pleguezuelos et al. [32] considered T. graeca rather as a non-threatened species and is categorized Least Concern (LC). However, T. graeca, like all reptiles native to Morocco, is protected by law since 1978, banning domestic and international trade. Despite these designations, large numbers of Moorish tortoises are still being removed from the wild in Morocco every year [33], mainly for European pet shops. Besides international traffic, T. graeca in Morocco, is threatened mostly by collecting for household pets and 'medicinal' use, for manufacture of tourist souvenirs. 
Znari et al. [13] reported on having counted not less than 692 T. graeca on offer in the souks (traditional markets) of Marrakech only in the period of July-August 2001. According to a more a recent survey conducted in 2013-2014 [33], 40\% of shops selling tortoises throughout Morocco are found in Agadir (9\%) and Marrakech (31\%). Given that tortoises were reported to have been sourced near the cities in which they are sold; the subspecies most likely to be present in Marrakesh and Agadir is T. g. soussensis. The shops in these two cities sell around $16 \%(520 / 3270)$ of the total number of tortoises offered in 12 cities in Morocco; with an average number of 47-95 individuals per shop, respectively in Agadir and Marrakech; the global average being 82 tortoises. The annual turnover range is $195-782$ tortoises with a monetary value of USD 1800-7200. Of about 900 tortoises measured, two-thirds measured $<100 \mathrm{~mm}$ $(<2-8$ years of age) and $<3 \%$ could comprise first-year individuals. Znari et al. [13] reported a similar percentage of $65.5 \%$ for $<100 \mathrm{~mm}$ small-sized tortoises from the tourist-trade shops in Marrakech while the corresponding percentages from the natural populations ranged from only 8 to $23 \%$ in west-central Morocco (Marrakech, Essaouira and Agadir areas) [6, 13].

Tortoises are long-lived animals with high adult survival rates, late sexual maturity, low hatching and juvenile survival rates and a specialized diet. Because of this, increases in adult mortality due to overexploitation of adult specimens in a tortoise population will have longterm impacts on the population viability, making them very sensitive to the pet trade $([7,18$, 22, 33]. Bayley and Highfield [5] indicated that the population of tortoises observed in the lower Souss Valley near Agadir was not sustainable; the age sex structure showed a marked predominance of males and a notably small percentage of juveniles. This could be the same case for the population of the central Jbilet [22] and maybe other populations in west-central Morocco. The lower Souss Valley is not currently subject to collecting, although it was a collecting area in the past [4]. However, the current population structure has also been adversely affected by the severe environmental degradation, this area has suffered as a result of the collection of wood, overgrazing and cultivation resulting in deforestation and soil erosion both of which result in a serious reduction in availability of plant fodder which forms the natural diet of T. graeca. The acute loss of the endemic Argan tree in this region is a major factor in the loss of wild fodder plants as the forest canopy provided shade and permitted seedlings to survive [5].

In other parts of Morocco, like the Jbilet Mts, the jujube, Z. lotus, suffers from officially promoted programs of removal. Testudo g. soussensis is threatened by such habitat loss, as tortoises must navigate between microhabitats to find essential feeding resources and thermal refuges. They depend on the occurrence of large and relatively abundant bushes to escape lethal overheating [8] and to find food resources [7].

\section{Conservation and restoration potentials}

An analysis of the conservation and restoration potentials of T. g. soussensis and its degraded habitat in arid areas of west central Morocco, revealed great opportunities of measures and actions to be carried out in favor of the safeguard of the declining populations of the Souss 
Valley tortoise [22]. Thus, an experimental captive breeding essay including a survey of reproduction, natural and artificial incubations of eggs and rearing of young captive-born tortoises, were carried out. Newly hatched tortoises, collected in the natural habitat, have been also hand-reared in the framework of a Head Starting operation, and were released in the wild at an age of 3-5 years for the reinforcement of remnant populations where the tortoises disappeared. Furthermore, actions of habitat restoration relying on replanting jujube bushes are proposed and consist, according to the level of environment deterioration, of an improved resource management or the reintroduction of the Jujube shrub and tortoises, which depend on. Finally, creating a tortoise sanctuary in the central Jbilet, reinforcing and connecting populations through replanting, are proposed. Protection of jujube bushes could considerably improve local habitats and biodiversity in arid steppe-lands of west-central Morocco (see also [8]).

\section{Conclusion}

The Souss Valley tortoise, T. g. soussensis, a morphologically-based subspecies, is an endemic to west-central Morocco. Its taxonomic status was confirmed by recent mitochondrial DNA data. Geographically-distant populations of this subspecies are morphologically, but not genetically differentiated. These tortoises occur in semi-arid to arid low quality habitats and their distribution, which is sensitive to precipitations, would have been shifted northwards since the Last Glacial Maxima. They are strictly herbivorous relying mostly on few fodder plants. They spend most of their time under bushes (especially larger ones) to avoid overheating and for more available fodder plants. Growth rate is relatively high in juveniles and then slows down in both sexes after sexual maturity. Adult females are larger than males with a relatively delayed sexual maturity. As in other subspecies, mating occurs in spring and early autumn and fecundity is relatively low as indicated by the small average clutch size. Population structure is characterized by very low proportions of juveniles and old adults along with a male-biased sex ratio. Most of populations are declining mainly due to overcollecting for pet trade as well as other threats related to human disturbances. Due to their soft carapace, hatchlings are particularly exposed to a high predation pressure. Most of tortoises are infested by ixodid ticks and Salmonella. Actions required for improving the conservation status for this threatened tortoise in arid areas of west-central Morocco are proposed, including habitat restoration and captive breeding for population reinforcement.

\section{Acknowledgements}

We are very indebted to all students and colleagues who helped in the field and/or laboratory works, especially M Naimi and S Namous; with a special thank to the inhabitants of Douar (small village) Salas. We would like to thank all colleagues who collaborated in various aspects of our research works, namely M Carretero, JD Harris, D Germano, J Anadon and JC Macé. Finally, we would like to thank the British Ecological Society, UK for the grant they provided for research on trophic and nutritional ecology of Testudo graeca soussensis in the Jbilet Mountains. 


\section{Conflict of interest}

There is no conflict of interest between the two authors about the content of the present chapter.

\section{Author details}

Mohammed Znari* and Nawal Hichami

*Address all correspondence to: znarim@gmail.com

Faculty of Science-Semlalia, Department of Biology, Laboratory of Biodiversity and Ecosystem Dynamics, Cadi Ayyad University, Marrakech, Morocco

\section{References}

[1] Schleich HH, Kästle W, Kabisch K. Amphibians and Reptiles of North Africa. Koenigstein: Koeltz Scientific Books; 1996. p. 630. ISBN-13: 978-3874293778

[2] Anadón JD, Giménez A, Graciá E, Pérez I, Ferrández M, Fahd S, EL Mouden EH, Kalboussi M, Jdeidi T, Larbes S, Rouag R, Slimani T, Znari M, Fritz U. Distribution of Testudo graeca in the Western Mediterranean according to climatic factors. AmphibiaReptilia. 2012;33:285-296. DOI: 10.1163/156853812X643710

[3] Lambert MRK. Studies on the growth, structure and abundance of the mediterranean spur-thighed tortoise, Testudo graeca, in field populations. Journal of Zoology. 1982; 196:165-189

[4] Lambert MRK. Some factors influencing the Moroccan distribution of the western Mediterranean spur thighed tortoise, Testudo graeca graeca L. and those precluding its survival in NW Europe. Zoological Journal of the Linnean Society. 1983;79(2):149-179

[5] Bayley JR, Highfield AC. Observations on ecological changes threatening a population of Testudo graeca graeca in the Souss Valley, Southern Morocco. Chelonian Conservation and Biology. 1996;2:36-42

[6] Carretero MA, Znari M, Harris DJ, Macé JC. Morphological divergence among populations of Testudo graeca from west-central Morocco. Animal Biology. 2005;55:259-279

[7] El Mouden EH, Slimani T, Ben Kaddour K, Lagarde F, Ouhammou A, Bonnet X. Testudo graeca graeca feeding ecology in an arid and overgrazed zone in Morocco. Journal of Arid Environments. 2006;64:422-435. DOI: 10.1016/j.jaridenv.2005.06.010

[8] Lagarde F, Louzizi T, Slimani T, El Mouden H, Ben Kaddour K, Moulherat S. Bushes protect tortoises from lethal overheating in arid areas of Morocco. Environmental Conservation. 2012;39:172-182. DOI: 10.1017/S0376892911000634 
[9] Moulherat S, Delmas V, Slimani T, El Mouden EH, Louzizi T, Lagarde F, Bonnet X. How far can a tortoise walk in open habitat before overheating? Implications for conservation. Journal for Nature Conservation. 2014;22:186-192. DOI: /10.1016/j.jnc.2013.11.004

[10] Hichami N, Znari M, Naimi M, Namous S. Clutch, egg and hatchling characteristics in the Souss Valley tortoises, Testudo graeca soussensis Pieh, 2001 (Testudines: Testudinidae) from an arid steppe-land of west-central Morocco. African Journal of Herpetology. 2016;65(1):21-32. DOI: 10.1080/21564574.2015.1136701

[11] Pieh A. Testudo graeca soussensis, eine neue Unterart der Maurischen Landschildkröte aus dem Sousstal (Nordwest-Marokko). Salamandra. 2001;36:209-222

[12] Harris DJ, Znari M, Macé JC, Carretero MA. Genetic variation in Testudo graeca from Morocco estimated using 12S rRNA DNA sequencing. Revista Española de Herpetología. 2003;16:5-9

[13] Znari M, Germano DJ, Macé JC. Growth and population structure of the Moorish tortoise (Testudo graeca graeca), in western central Morocco: Possible effect of over-collecting for the tourist trade. Journal of Arid Environments. 2005. DOI: 10.1016/j.jaridenv.2004.11.013

[14] Ben Kaddour K, El Mouden EH, Slimani T, Bonnet X, Lagarde F. Sexual dimorphism in the Greek Tortoise: A test of the body shape hypothesis. Chelonian Conservation and Biology. 2008;7:21-27. DOI: 10.2744/CCB-0649.1

[15] Highfield AC, Martin J. Testudo whitei Bennet 1839. New light on an old carapace-Gilbert White's Selborne tortoise re-discovered. Journal of Chelonian Herpetology. London. 1989; 1(1):13-22

[16] Highfield AC. Tortoises of north Africa; taxonomy, nomenclature, phylogeny and evolution with notes on feld studies in Tunisia. Journal of Chelonian Herpetology. London. 1990;1(2):1

[17] Fritz U, Harris DJ, Fahd S, Rouag R, Martínez EG, Casalduero AG, Široký P, Kalboussi M, Jdeidi TB, Hundsdörfer AK. Mitochondrial phylogeography of Testudo graeca in the Western Mediterranean: Old complex divergence in North Africa and recent arrival in Europe. Amphibia-Reptilia. 2009;30:63-80. DOI: 10.1163/156853809787392702

[18] Schweiger M. Herpetologische Beobachtungen im Gebiet von Ouarzazate (Marokko). Herpetozoa, Vienna. 1992;5(1/2):13-31

[19] Bons J, Geniez P. Amphibiens et Reptiles du Maroc (Sahara Occidental compris). Atlas biogéographique. Barcelona (Asociación Herpetológica Española). 1996:320

[20] Pieh A, Perälä J. Variabilität der Maurischen Landschildkröten (Testudo graeca Linnaeus, 1758 - Komplex) im zentralen und nordwestlichen Marokko mit Beschreibung zweier neuer Taxa. Herpetozoa. 2004;17:19-47

[21] Anadón JD, Graciá E, Botella F, Giménez A, Fahd S, Fritz U. Individualistic response to past climate changes: Niche differentiation promotes diverging Quaternary range 
dynamics in the subspecies of Testudo graeca. Ecography. 2015;38(9):956-966. DOI: 10. 1111/ecog.01163

[22] Hichami N. Ecophysiology \& Conservation ecology of the Souss Valley tortoises, Testudo graeca soussensis Pieh, 2001 (Testudines: Testudinidae), in an arid area of west central Morocco [thesis]. Faculty of Science-Semlalia, Marrakech, Morocco: Cadi Ayyad University; 2017

[23] Lovich JE, Gibbons JW. A review of techniques for quantifying sexual size dimorphism. Growth, Development and Aging. 1992;56:269-281

[24] Krüger E. Near-natural incubation of Testudo graeca soussensis Pieh, 2000. Eggs. Radiata. 2007; 16:42-43

[25] Sereau M, Lagarde F, Bonnet X, El Mouden EH, Slimani T, Dubroca L, Trouvé C, Dano $\mathrm{S}$, Lacroix A. Does testosterone influence activity budget in the male Greek tortoise (Testudo graeca graeca)? General and Comparative Endocrinology. 2010;167:181-189. DOI: 10.1016/j.ygcen.2010.03.002

[26] Keller C, Diaz-Paniagua C, Andreu AC. Survival rates and causes of mortality of Testudo graeca hatchlings in south western Spain. Journal of Herpetology. 1998;32:238-243. DOI: $10.2307 / 1565303$

[27] Boarman WI. Reducing predation by Common Ravens on Desert Tortoises in the Mojave and Colorado deserts. USGS: Science for a Changing World; 2002. p. 39

[28] Barje F, Slimani T, EL Mouden EH, Lagarde F, Bonnet X, Ben Kaddour K. Shrewd shrikes and spiny shrubs: A calmity for hatchling Moorish tortoises (Testudo graeca graeca). Amphibia-Reptilia. 2005;26:113-115. DOI: 10.1163/1568538053693341

[29] Kireçci E, Özer A, Balkaya I, Taniş H, Deveci S. Identification of Ticks on Tortoises (Testudo graeca) and Investigation of Some Pathogens in these Ticks in Kahramanmaraş, Turkey. KSU Journal of Natural Sciences. 2013;16(1):42-46

[30] Hidalgo-Vila J, Diaz-Paniagua C, Ruiz X, Portheault A, El Mouden EH, Slimani T, Frutos-Escobar C, De Caso MS. Salmonella in free-living spur-thighed (Testudo graeca) from Central Western Morocco. Veterinary Record. 2008;162(7):218-219

[31] Lambert MRK. On growth of captive-bred Mediterranean Testudo in N. Europe. In: Rocek Z, editor. Studies in Herpetology. Prague: Charles University; 1985. pp. 309-314

[32] Pleguezuelos JM, Brito JC, Fahd S, Feriche M, Mateo JA, Rueda GM, Reques R, Santos $X$. Setting conservation priorities for the Moroccan herpetofauna: The utility of regional red lists. Fauna \& Flora International, Oryx. 2010;44(4):501-508. DOI: 10.1017/ S0030605310000992

[33] Nijman V, Bergin D. Trade in spur-thighed tortoises Testudo graeca in Morocco: volumes, value and variation between markets. Amphibia-Reptilia. 2017;38(3):1-13. DOI: 10. 1163/15685381-00003109 
